\title{
SHOCK-INDUCED DEFECTS IN HgO
}

\author{
B. Morosin, E. L. Venturini, G. T. Holman, \\ P. N. Newcomer, R. G. Dunn, and R. A. Graham \\ Sandia National Laboratories, Albuquerque, NM 87185-1421
}

Powder compacts of $\mathrm{HgO}$ have been subjected to shock-loading and preserved for post-shock analysis to understand its reactivity and stability under transient temperature-pressure excursions. Recovered samples indicate several solid state reactions which are dependent on shock conditions. Metallic $\mathrm{Hg}$ is recovered in small amounts in the $\mathrm{HgO}$ compact as well as an as-yet unidentified ferromagnetic impurity not present in the as-received $\mathrm{HgO}$ powder. Further, there is evidence of reaction with the copper capsule at its interface with the $\mathrm{HgO}$ powder, forming an intermetallic alloy.

\section{INTRODUCTION}

Our synthesis experiments on Hg-containing superconductors showed $\mathrm{HgO}$, known to decompose near $500^{\circ} \mathrm{C}$, could be subjected, in the presence of other oxides, to rapid temperature excursions above $800^{\circ} \mathrm{C}$ without significant $\mathrm{HgO}$ decomposition (1). Prior to employing a shock-induced chemical synthesis route similar to our previous work $(2,3)$ for the formation of $\mathrm{Hg}$-containing superconductors (for which some phases are formed only under high static pressure environments), the properties of $\mathrm{HgO}$ under similar conditions were considered desirable. This note reports on powder compacts of $\mathrm{HgO}$ subjected to a variety of shock conditions appropriate for such synthesis.

\section{EXPERIMENTAL}

Commercially available $\mathrm{HgO}$ from Alfa/Aesar (reagent grade, stock \#12276, lot \#b15e10) was employed "as-received" in this study under careful conditions both in preparing and loading the powder compacts and in the subsequent analysis because of environmental concerns. This source of material was shown by $x$-ray diffraction to be the usual orthorhombic form of $\mathrm{HgO}$ (Space group Pnma with cell edges 6.6121, 5.5201 , and $3.5213 \AA$ ). Another form isomorphic with cinnabar, $\mathrm{HgS}$, is of hexagonal symmetry with $\mathrm{a}=3.577$ and $\mathrm{c}=8.681 \AA$. The orthorhombic form has infinitely long zigzag but planar chains of mercury and oxygen atoms extending along the a-axis while the hexagonal form is a distortion of the $\mathrm{NaCl}$ arrangement and is very slightly more dense with 32.06 $\AA^{3} /$ molecule (verses $32.13 \AA^{3}$ /molecule for the orthorhombic form ). The powder is orange in color. The X-ray line profiles of this powder were shown to be slightly broadened, consistent with a crystallite domain size near $1500 \AA$.

The pressed (to $\sim 55 \%$ theoretical density) compacts were subjected to controlled shock compression conditions to peak pressures in the Sandia Bear recovery fixtures described and characterized previously (4). The shock conditions used in this study are given in Table 1. Each experiment yielded several samples, denoted as a "center" or "outer", corresponding to the location of the powder compact within the shock recovery fixture. Each sample experienced a different mean bulk temperature, as shown in the table. 


\section{DISCLAIMER}

This report was prepared as an account of work sponsored by an agency of the United States Government. Neither the United States Government nor any agency thereof, nor any of their employees, makes any warranty, express or implied, or assumes any legal liability or responsibility for the accuracy, completeness, or usefulness of any information, apparatus, product, or process disclosed, or represents that its use would not infringe privately owned rights. Reference herein to any specific commercial product, process, or service by trade name, trademark, manufacturer, or otherwise does not necessarily constitute or imply its endorsement, recommendation, or favoring by the United States Government or any agency thereof. The views and opinions of authors expressed herein do not necessarily state or reflect those of the United States Government or any agency thereof. 


\section{DISCLAIMER}

Portions of this document may be illegible in electronic image products. Images are produced from the best available original document. 
TABLE 1. Schedule of Shock Experiments (a)

\begin{tabular}{|c|c|c|c|c|}
\hline \multirow{2}{*}{\multicolumn{2}{|c|}{ Experiment }} & $\begin{array}{l}\text { Compact } \\
\text { Density }\end{array}$ & $\begin{array}{l}\text { Peak } \\
\text { Press. }\end{array}$ & $\begin{array}{l}\text { Mean Bulk } \\
\text { Temp. (b) }\end{array}$ \\
\hline & & $\mathrm{Mg} / \mathrm{m}^{3}(\%)$ & $\mathrm{GPa}$ & ${ }^{\circ} \mathrm{C}$ \\
\hline & $M B A-C$ & & 22 & 400 \\
\hline & MB-F & 6.03( & 7.5 & $225(3$ \\
\hline LE95-50 & PB-B & $5.90(53)$ & 5.0 & $150(75)$ \\
\hline
\end{tabular}

(a) For more detailed descriptions of pressure and temperature, see ref 4. MBA, MB, and $\mathrm{PB}$ indicate the Momma Bear A, Momma Bear, and Pappa Bear fixtures while $-C B$ and $-B$ the composition $\mathrm{B}$ and baratol explosives; respectively.

(b) The calculated mean bulk temperature in the center and in parenthesis, the outer ring of the samples are shown.

X-ray diffraction data were taken using a commercial Rigaku $\Theta-\Theta$ automated powder diffractometer equipped with a monochrometer on the detector set so both $\mathrm{CuK} \alpha_{1}$ and $\mathrm{CuK} \alpha_{2}$ radiation were obtained.

Transmission electron microscopy (TEM) specimens were prepared by dispersion of shockloaded as well as the as-received $\mathrm{HgO}$ powders onto the holey carbon film of copper grids. A JEOL 1200EX TEM instrument at $120 \mathrm{KV}$ was employed. On most samples, both bright field imaging and dark field diffraction were carried out on selected grains.

The diamagnetism characteristic of mercury materials as well as that for superconductivity of trace amounts of metallic $\mathrm{Hg}$ were demonstrated by low temperature static magnetization data collected using our commercial SQUID magnetometer (Quantum Design model MPMS).

\section{RESULTS}

Experiment LE95-22 ruptured during shockloading and did not yield any powder compact samples. The recovered sample-copper interface showed the same dull silver layer that the LE9523 experiment also showed. The recovered powder compacts of the other two shock experiments were separated into four samples, as described below, and together with parts of the interface layer, subjected to $x$-ray, TEM, and magnetization studies.

\section{Sample Preparation}

The recovered sample compact was removed essentially whole, but was somewhat fragile, particularly for the extreme edge of LE95-23 ( resulting in a sample designated as "extreme edge" ) while a thin layer of powder adjacent to the top plug of LE95-50 stuck to the copper fixture plug and was hence separated from the compact, gently scraped from the plug, and designated as " top plug". The other samples resulted from separating the compact into the usual "center", "bulk", and "edge" samples. The edge samples appeared slightly more reddishbrown than the original orange color while the top plug sample appeared slightly more reddish. The center of the LE95-50 and the extreme edge of the LE95-23 samples were a bit more consolidated than the remainder of the samples and required more gentle grinding so as to pass through a $0.2 \mathrm{~mm}$ screen.

\section{X-ray Diffraction Studies}

X-ray diffraction measurements on a specimen of the dull silver interface cut from the lid of experiment LE95-23 showed that it was the intermetallic compound $\mathrm{Cu}_{15} \mathrm{Hg}_{11}$. This alloy crystallizes in space group $\mathrm{R} 3 \mathrm{~m}$ with $\mathrm{a}=\mathbf{1 3 . 3 5 1}$ and $c=16.175 \AA$, a rhombohedrally distorted gamma brass structure type. Note that the corresponding rhombohedral cell would be $a=$ $9.4067 \AA, \alpha=90.413^{\circ}$ and, hence, this intermetallic has occasionally been reported as cubic. This intermetallic has also been confirmed by EDAX on SEM specimen.

$X$-ray diffraction showed only the orthorhombic form of $\mathrm{HgO}$ with no detectable traces of any other compound. The presence of well dispersed liquid $\mathrm{Hg}$ metal droplets, if present (see below) would not be detected at low concentration by the 
usual $x$-ray diffraction experiment. There were no discernable differences between either the more reddish top plug or the reddish brown extreme edge and the other samples. The $x$-ray line profiles were all, but with the exception of the center LE95-50 sample, slightly narrower than the initial as-received or "standard" powder employed in the experiments. The line widths for most of the shock-loaded samples are consistent with those for a well annealed $\sim 200$ $\mathrm{nm}$ or larger crystalline domain-sized material, essentially those obtained for our Si powder previously run on our diffractometer. The single exception had line widths essentially the same as the standard and of the order of $\sim 140 \mathrm{~nm}$. This prevents any quantitative profile analysis using these samples. It was subsequently concluded that the gentle grinding on the LE95-50 "center" sample was sufficient to reduce the grains (crystallite domain size) because of the van der Waal interactions between the $\mathrm{HgO}$ zigzag chains of the crystal structure.

\section{TEM Studies}

TEM bright field imaging was used to determine the size and microstructure of the shock-loaded and as-received $\mathrm{HgO}$ grains. $\mathrm{HgO}$ proved to be very sensitive to the electron beam. All of the $\mathrm{HgO}$ grains observed break up into a fibrous morphology when exposed to a focused electron beam. Because of this sensitivity, detailed microstructural study is difficult; however, some changes in the shock-loaded samples were observed.

While the as-received grains were typically $100-300 \mathrm{~nm}, 500-1500 \mathrm{~nm}$ grains for the edge sample of LE95-23, where the temperature is greatest, and 300-1000 $\mathrm{nm}$ for the center sample indicates grain growth, possibly occurring after the shock event. The lower temperature LE9550 samples showed a smaller amount of grain growth. The edge sample consisted of 200-700 $\mathrm{nm}$ grains, with fine grains of fibrous-like clusters, less than $50 \mathrm{~nm}$ in size found between the larger grains. The center of this sample showed a substantial amount of these fine grained fibrous-like clusters; however, recall that this sample was ground a bit more than the other samples. Occasionally, a second phase was found among these clusters which under the electron beam appeared to move. These were subsequently believed to be small droplets of metallic $\mathrm{Hg}$ (see below).

\section{Magnetic Properties Studies}

The magnetic properties of the recovered $\mathrm{HgO}$ samples were examined at temperatures between 2 and $300 \mathrm{~K}$ in applied magnetic fields up to 5 tesla. The as-received $\mathrm{HgO}$ powder employed in this study contains a significant paramagnetic impurity phase. Pure $\mathrm{HgO}$ has a small diamagnetic susceptibility at room temperature, $2.03 \times 10^{-7} \mathrm{~cm}^{3} / \mathrm{g}$. In contrast, the as-received $\mathrm{HgO}$ is dominated by the impurity phase. Assuming the paramagnetism arises from a spin $=1 / 2$, g-factor $=2$ ion, approximately $0.4 \%$ impurity ions per $\mathrm{Hg}$ are present.

In contrast, the shock-loaded samples exhibit a large positive moment at $300 \mathrm{~K}$ which increases dramatically with peak shock temperature and pressure, reaching $+3.3 \times 10^{-3} \mathrm{emu} / \mathrm{g}$ for the "outer extreme" LE95-23 sample. All four LE95-23 shock-loaded samples exhibit a roughly linear increase in moment with decreasing temperature, and the slopes are remarkably similar for the different shock conditions. The large positive moment at $300 \mathrm{~K}$ is attributed to an unknown ferromagnetic impurity introduced (formed) during shock loading. The nonlinear behavior of the magnetic moment verses applied field at $5 \mathrm{~K}$, after the appropriate corrections for the plastic sample container and the reference asreceived $\mathrm{HgO}$ powder, is characteristic of "hard" ferromagnetic materials where the moment "saturates" in large applied magnetic fields. The extreme outer LE95-23 has a ferromagnetic "saturation" value of $1.2(1) \times 10^{-2} \mathrm{emu} / \mathrm{g}$. If the unknown ferromagnetic impurity were magnetite, $\mathrm{Fe}_{3} \mathrm{O}_{4}$, with a saturation moment of $97 \mathrm{emu} / \mathrm{g}$ at low temperatures, this sample response would arise from an impurity level of $0.01 \%$ by weight. It is conceivable that shock 
loading transforms about $3 \%$ of the paramagnetic impurity in the as-received $\mathrm{HgO}$ to a ferromagnetic phase.

The magnetic measurements also showed evidence for a small superconducting component in the shock-loaded $\mathrm{HgO}$ powders. In a magnetic field of 0.5 millitesla, sufficiently small so that the contribution for the just mentioned ferromagnetic impurity is negligible, data measured with decreasing temperatures from 5 to $2 \mathrm{~K}$ indicated the appearance of a substantial negative magnetic moment below a transition temperature, i.e., the onset of superconductivity. This negative moment arises from the Meissner effect (expulsion of the applied field from the superconducting grains.) All of the four LE9523 samples show a superconducting transition just below $4.2 \mathrm{~K}$, consistent with metallic $\mathrm{Hg}$. Since the as-received $\mathrm{HgO}$ powder showed no evidence for superconductivity, the shockloading converts a small quantity of the $\mathrm{HgO}$ to $\mathrm{Hg}$. These data suggest that the amount of metallic $\mathrm{Hg}$ increases going from the center, bulk, edge and extreme edge samples, $-2.4,-4.0$, -5.0 and -31 . (all $\times 10^{-4} \mathrm{emu} / \mathrm{g}$ ), respectively, at 2 $\mathrm{K}$.

\section{CONCLUDING REMARKS}

There is strong evidence that metallic $\mathrm{Hg}$ is formed for samples subjected to the shock conditions of experiment LE95-23. This suggests that even under pressure of $7.5 \mathrm{GPa}$, with a mean bulk temperature rise to $\sim 225{ }^{\circ} \mathrm{C}$, $\mathrm{HgO}$ is decomposing into metallic $\mathrm{Hg}$ and that the $\mathrm{Hg}$ adjacent to the $\mathrm{Cu}$ fixture is sufficiently reactive to form the intermetallic compound $\mathrm{Cu}_{15} \mathrm{Hg}_{11}$. At locations away from the $\mathrm{Cu}$ interface, this $\mathrm{Hg}$ coalesces into microdroplets.

These microdroplets reside between the grains and were disturbed by the heating effect of the TEM electron beam. The beam also frayed and defoliated the $\mathrm{HgO}$ grains, showing the weak van der Waal interaction between the zigzag chains in the crystal structure of this orthorhombic form.

Further, at these low mean bulk shock-induced temperatures, the $\mathrm{HgO}$ is able to significantly (x5) enlargen its grain size as evidenced by TEM bright field imaging. The lack of breadth of the $x$-ray lines beyond that resulting from the usual experimental diffraction optics is additional evidence for annealing at these low temperatures. Together, these results rule out the possibility of a pressure induced reversible phase transition consistent with the small reported density difference of the two forms.

Also of significance were the magnetic measurements of the as-yet unidentified impurity formed from the shock environment and possibly involving the metallic $\mathrm{Hg}$ present. Such low level detection of phases may prove useful in other shock studies.

On a more general vein, the present materials study contributes towards resolving several shock issues concerning our Bear fixtures and $\mathrm{TiO}_{2}$ model calculations. Although there remains ambiguities whether events occur at pressure or result from post-shock effects, the major shock effects are consistent with previous studies. That is, there is no radial focusing in the LE95-50 experiment, leading to a more uniform pressure over the entire sample in contrast to LE95-23. .

\section{ACKNOWLEDGMENTS}

The assistance of Marvin Banks at the New Mexico Tech Center for Explosives Technology Research, Socorro, NM is gratefully acknowledged. This work was supported by the United States Department of Energy under Contract No. DE-AC04-94AL85000.

\section{REFERENCES}

1. Morosin, B., Venturini, E.L., Schirber, J.E., and Newcomer, P.P., PhysicaC 226, 175-183 (1994).

2. Morosin, B., Graham, R.A., Venturini, E.L., Ginley, D.S. and Hammetter, W.F., "Shock-Induced Chemical Synthesis of Phases Similar to the High Temperature Superconductor Oxides," Proceedings of the Conference on Shock Waves in Condensed Matter, 1987, pp 439-442.

3. Morosin, B., Graham, R.A. Venturini, E.L., and Ginley, D.S., Synthetic Metals 33, 175-183 (1989).

4. Graham, R.A., Solids Under High Pressure Shock Compression-Mechanics, Physics, and Chemistry. New York: Springer-Verslogen, 1993, 151-is9. 